\title{
LINGUAGENS DO INSÓLITO: A CONSTRUÇÃO ESTILÍSTICO-TEXTUAL DO GROTESCO NA FICÇÃO DECADENTE
}

Daniel Augusto (UERJ)

Recebido em 29 set 2017. Daniel Augusto P.Silva é Mestrando em Teoria da Aprovado em 17 out 2017.

Literatura e Literatura Comparada na Universidade do Estado do Rio de Janeiro e bolsista CAPES sob orientação do Prof. Dr. Júlio França (UERJ). Além disso, integra o Grupo de Pesquisa Estudos do Gótico (CNPq). É coorganizador do livro Páginas Perversas: narrativas brasileiras esquecidas (Appris, 2017).

Resumo: Tanto a literatura gótica quanto a ficção fantástica empregaram técnicas características das poéticas do grotesco para criar personagens e situações não apenas sobrenaturais, mas também capazes de causar horror e repulsa como efeitos de recepção. Por gerar seres disformes, sem unidade aparente e de difícil subsunção a categorias racionais, a arte grotesca é, de fato, pródiga em produzir tanto a hesitação própria ao fantástico quanto o medo essencial às narrativas de horror. No final do século XIX, a ficção decadente, tributária dessas duas tradições literárias, em sua busca por experiências estéticas originais e intensas, valeu-se sistematicamente de procedimentos típicos do grotesco literário. Este trabalho irá se centrar na descrição dos elementos grotescos no plano estilístico, como a partir do uso recorrente de neologismos e de palavras raras, de 
construções sintáticas inesperadas, além de inversões na ordem típica das estruturas sintagmáticas. Ao contrário do que a crítica muitas vezes apontou, tal estilo de escrita não foi fruto de uma erudição vazia ou de simples diletantismo artístico; na verdade, sua utilização foi intencional, voltada exatamente para intensificar a fruição estética. A fim de demonstrar o emprego dessas estratégias textuais e estilísticas empregadas pela ficção decadente, analisamos trechos do romance Là-bas (1891), de J.-K. Huysmans, e o conto "Agonia por semelhança", publicado por Gonzaga Duque em Horto de mágoas (1914).

Palavras-chave: Decadência; Fantástico; Gótico; Impressionismo literário; Écriture artiste.

Abstract: Both Gothic and Fantastic fiction have employed techniques characteristic of the poetics of the Grotesque to create characters and situations not only supernatural but also capable of causing horror and disgust as reception effects. By generating monstrous beings, with no apparent unity and of difficult subsumption to rational categories grotesque art is, in fact, prodigal in producing the hesitation proper to the Fantastic and the essential fear to the Horror Narratives. At the end of the nineteenth century, the Decadent Fiction, tributary of these two literary traditions, in its search for original and intense aesthetic experiences, was systematically based on procedures typical of the literary grotesque. This paper will focus on the description of the grotesque elements in the stylistic plan, such as the recurrent use of neologisms and rare words, unexpected syntactic constructions, as well as inversions in the typical order of the syntagmatic structures. Contrary to what criticism has often pointed out, this style of writing was not the fruit of an empty erudition or simple artistic dilettantism; actually, its use was intentional, geared precisely to intensify the aesthetic pleasure. In order to demonstrate the use of these textual and 
stylistic strategies employed by Decadent Fiction, we analyze excerpts from the novel Là-bas (1891), by J.-K. Huysmans, and the short story "Agonia por semelhança", published by Gonzaga Duque in Horto de mágoas (1914).

Keywords: Decadence; Fantastic; Gothic; Literary Impressionism; Écriture artiste.

\section{DISCURSOS FANTÁSTICOS}

Desde as origens da literatura fantástica, os autores desse modo ficcional se confrontam recorrentemente com a seguinte questão: como expressar exatamente o inominável, o sobrenatural, o irreal e o que rompe com nossas categorizações racionais? As soluções narrativas e textuais encontradas para esse problema foram, historicamente, bastante diversas e deram forma literária não apenas a figuras monstruosas como vampiros, lobisomens e zumbis, mas também a usos específicos da linguagem. Tanto nas obras fantásticas stricto sensu quanto no espectro mais amplo das produções insólitas (GARCíA, 2012), a recorrência de certas escolhas linguísticas aponta para uma peculiaridade discursiva desse tipo de literatura - seja no gótico literário, na prosa de ficção decadente ou na ficção de horror contemporânea.

Vários estudos foram empreendidos a fim de comparar a linguagem de tais obras com a de produções literárias de explícito caráter mimético. Apesar da identificação frequente de certos procedimentos estilísticos nas narrativas de cunho fantástico, é ponto pacífico para a crítica que as mesmas estratégias textuais possam estar presentes tanto na literatura de cunho sobrenatural quanto na de cunho realista. A demarcação de diferenças formais 
pode ser rastreada, contudo, na reiteração de alguns procedimentos narrativos, na combinação de alguns recursos linguísticos, e na busca por gerar efeitos de recepção como o medo, a repulsa e a hesitação. Como afirma David Roas, "não existe uma linguagem fantástica em si mesma, e sim um modo de usar a linguagem que gera um efeito fantástico" (2014, p.179).

Para analisar esse modo de escrita e suas convenções artísticas, o crítico espanhol aborda o fantástico como um "problema de linguagem" (ROAS, 2013, p.61), em virtude do trabalho textual de tais narrativas em expressar situações e personagens que infringem as leis da realidade. Para a transgressão ao real ser bem-sucedida e impactar o público-leitor, não bastaria a mera descrição de eventos e criaturas sobrenaturais; ao contrário, antes da aparição dos elementos responsáveis por subverter nossas categorizações racionais, seria preciso, primeiro, representar o mundo cotidiano de modo verossímil e até mesmo realista. Após essa etapa inicial da estruturação do texto fantástico, no momento da manifestação insólita, os narradores costumariam fazer uso de uma imprecisão linguística para descrever esses eventos surpreendentes e que ultrapassam os limites do conhecido. Eles explicitariam também outras estratégias para além da indeterminação discursiva, construindo um "conjunto de marcas textuais que assinala a excepcionalidade do representado" (ROAS, 2013, p.65). Entre os indícios arrolados pelo crítico, estariam, por exemplo, a literalização da conotação, a narração em primeira pessoa, a ambiguidade interpretativa, a quebra da causalidade e a preferência por uma temporalidade não linear.

Tzvetan Todorov já indicara aspectos semelhantes, ou mesmo coincidentes, em sua obra sobre o fantástico. Ainda que tenha se 
limitado à explicação de traços gerais, o autor também destacou a tendência das narrativas à imprecisão e ao exagero quando descrevem um fenômeno fantástico. Para dar ênfase a essa indefinição e criar um ambiente propício à ambiguidade sobre a realidade ou não dos fatos apresentados na diegese, os narradores se valeriam de estruturas linguísticas modalizadoras tais quais "parece" e "dir-se-ia', 'eles me chamariam', 'ter-se-ia dito', 'como se'"' (TODOROV, 2010, p.88). Além desses usos, as obras teriam o pretérito do imperfeito como tempo verbal preferido, por sua capacidade de indicar incerteza e inexatidão sobre a extensão dos acontecimentos.

De forma semelhante, Filipe Furtado (1980, p.135) estuda diversos procedimentos de construção da narrativa fantástica e analisa detidamente elementos formais como os narradores, os espaços, os enredos e as personagens. Essa literatura teria predileção, por exemplo, (i) por narradores homodiegéticos, que, aproximando o leitor do relato, confeririam maior adesão aos fatos narrados; (ii) por um espaço híbrido, o qual, ao mesmo tempo em que é construído para se parecer com os da realidade, apresenta progressivamente uma subversão dos locais conhecidos; (iii) por enredos que tematizem os limites do conhecimento científico e da curiosidade humana; (iv) por personagens que ora explicitam dúvida ora adesão aos fenômenos fantásticos a que se submetem. Essas estruturas teriam como objetivo garantir a ambiguidade necessária para o fantástico vir à tona nas narrativas.

Ganham ênfase também as estratégias textuais para garantir a verossimilhança dos fatos narrados. Os textos fantásticos apresentariam destacada "tendência tautológica" (FURTADO, 1980, p.131), ao formarem estruturas e paratextos - como diários, 
reportagens de jornal, cartas e outros tipos de relato - que reforçam continuamente a veracidade dos conteúdos previamente descritos. Esse tipo de literatura se caracterizaria, assim, "por uma permanente redundância, apontando continuamente para si próprio e para o que pretende veicular" (FURTADO, 1980, p.131).

Tributária dessa tradição literária e igualmente pertencente ao grupo de narrativas insólitas, a prosa de ficção decadente também empregou estratégias estilístico-textuais análogas às do fantástico, sobretudo no que diz respeito à criação de figuras grotescas. Em sua busca por práticas estéticas novas e intensas, tal ficção se notabilizou pelo seu trabalho formal e pela experimentação linguística. Com uma meta de originalidade, ela encontrou no grotesco literário não somente um modo de criar figuras disformes e horríveis, que expressassem sua visão de mundo negativa e desencantada, mas, sobretudo, uma maneira de explorar ao máximo as possibilidades discursivas e os recursos imagéticos da literatura.

Jean de Palacio (2011, p.18), um dos estudiosos dessa produção, considerou a ficção decadente não apenas em suas temáticas e em sua relação com um período histórico conturbado política e socialmente, mas também como uma "linguística", isto é, como um uso da linguagem que apresenta singularidades em relação a outras obras da época. Ao observar que esses textos estão repletos de neologismos, arcaísmos, termos raros e inversões sintáticas, levando, em certos casos, a uma dificuldade de compreensão e mesmo ao hermetismo, o autor sugere, hiperbolicamente, que "há um idioleto particular à Decadência. Podemos escrever em decadente, como faríamos em alemão ou em inglês"11 (p.34).

1 Todos os trechos de obras sem edição em língua portuguesa foram por mim traduzidos. 
Em virtude da falta de linearidade na construção frasal e estilística, Palacio (2011, p.36) classificou o estilo decadente como arabesco. Tal qualificação nos remete à própria arte arabesca, que, ao longo de diferentes estudos sobre arte decorativa, foi comparada e até aproximada ao grotesco. Wolfgang Kayser (1986, p.54) é um dos que aborda a similaridade, e indica, ainda, que tanto Goethe em Von Arabesken (1789) quanto Schlegel em Gespräch über die Poesie (1800) aproximam os dois tipos de produção, a ponto de o primeiro ter usado as duas palavras para indicar a mesma ideia. Se levarmos essa analogia em consideração, a classificação de Palacio sobre o estilo decadente também sugere um caráter grotesco dessa forma, como veremos mais detidamente nos outros tópicos.

De todo modo, a ficção decadente se desenvolveu em um momento de destacada renovação da linguagem literária, tanto na Europa quanto no Brasil. A partir da segunda metade do século XIX, diversas narrativas francesas passaram a empregar e a combinar, cada vez mais frequentemente, termos e expressões que até então não se faziam tão presentes na literatura. Além disso, trata-se de um período bastante profícuo para a criação de novas palavras e acepções semânticas. Esse é o estado da produção artística que Marcel Cressot nos revela:

Uma das primeiras certezas que se apresentam ao espírito do escritor de 1880, é que, em matéria de língua, exceção feita a algumas receitas imperiosas, ele goza de liberdade completa. A ele é permitido criar palavras, rejuvenescer aquelas que caíram em desuso, tomar emprestado termos dos vocabulários técnicos, dos dialetos, da língua de todos os dias, da gíria, das línguas estrangeiras. A ele é permitido associar às palavras um sentido 
que elas haviam perdido ao longo dos tempos, ou mesmo um sentido "surpreendente", sugerido por uma etimologia frequentemente aproximativa. As contagens efetuadas até esse momento nos dão apenas uma fraca ideia da abundância das aquisições da segunda metade do século XIX. $(1938, \text { p.3 })^{2}$

Nesse contexto de experimentação linguística, surge um modo estilístico que ficou conhecido sob o nome de écriture artiste. Tratase de uma forma de escrita bastante atrelada ao impressionismo literário, que visava destacar em detalhes os aspectos imagéticos e sensoriais de cada cena, dando mais importância aos efeitos das ações - visuais, sonoros, olfativos, gustativos e táteis - que aos próprios acontecimentos. Em tais procedimentos, que enfatizam a capacidade perceptiva das personagens e da recepção, é patente a influência tanto da teoria das correspondências de Baudelaire quanto da pintura moderna. Além desse ideário artístico, a écriture artiste expressou a "preocupação da frase trabalhada por ela mesma, 'cinzelada', [...] da frase objeto de arte, digna de ser contemplada e apreciada mais pela elegância, fineza e ousadia de suas formas que pelo que significa" (MITTERAND, 1985, p.467).

Autores vinculados a diferentes poéticas e gêneros literários empregaram tais técnicas estilísticas. Aécriture artiste se fez presente, em maior ou em menor grau, nas obras de poetas como Verlaine e Mallarmé, bem como nas narrativas de Edmond de Goncourt, Flaubert, Zola e Huysmans. Como podemos observar nessa curta enumeração, os procedimentos próprios da écriture artiste foram

2 Destacamos que algumas dessas experimentações linguísticas também foram empreendidas, anteriormente, por autores pertencentes ao chamado grupo dos petits romantiques, como, por exemplo, Pétrus Borel (1809-1859), cujas produções expressaram igualmente uma visão de mundo negativa e desencantada (BATALHA, 2013). 
utilizados inclusive por naturalistas, que, apesar da destacada preocupação mimética, não ignoraram o lado estético de suas obras. Será, no entanto, na prosa de ficção decadente que essa tendência se manifestará de maneira mais intensa, a ponto de ser também descrita como "língua da decadência" (CRESSOT, 1938, p.75).

Em um minucioso estudo estilístico da obra de J.-K. Huysmans, Cressot justifica sua compreensão de que a écriture artiste teria se tornado representativa da ficção decadente. Para o crítico, essa compreensão da estrutura linguística como um objeto estético em si mesmo levou a escolhas linguísticas pouco usuais, por vezes deliberadamente excêntricas, e que rompiam a ordem mais comum de termos nas frases, em uma inclinação "à anomalia" (CRESSOT, 1938, p.72). A maior valorização do efeito, em detrimento da precisão factual, levou os narradores a apresentarem os acontecimentos conforme eles são sentidos pelas personagens, por meio de uma estratégia discursiva que marca a quebra da ordenação mais comum e esperada dos eventos, recusando-se a seguir a cronologia empírica e lógica dos episódios.

Além de denominar de "língua da decadência", o autor classifica essas escolhas textuais que fogem às expectativas linguísticas como pertencentes a uma "estética da impropriedade" (CRESSOT, 1938, p.536). Ao criar neologismos, mudar o sentido de palavras, recuperar usos arcaizantes, usar estrangeirismos, Huysmans e, por extensão, a ficção decadente, buscariam formar uma linguagem artificial, que fosse capaz de gerar uma sensação de "dépaysement" (CRESSOT, 1938, p.541), isto é, de estranhamento, para a recepção.

Em virtude desses exercícios estilísticos que produzem incômodo na leitura, bem como do aspecto lúdico na criação textual, o crítico 
compara Huysmans a Rabelais, o grande nome da literatura grotesca na França. Ambos teriam se dedicado a "exercícios de virtuosidade" linguística, que expressariam a "lógica levada ao absurdo" (CRESSOT, 1938, p.557). Ainda que não mencione expressamente o conceito de grotesco e não desenvolva essa comparação, ele tem razão ao encontrar semelhanças entre os dois autores. Ressaltamos, ainda, que ambos promoveram o grotesco não só no plano estilístico, com essa linguagem tortuosa e não linear, como também no temático, com figuras bastante disformes.

Ao contrário de Cressot, Mitterand adota um juízo crítico negativo sobre o estilo decadente, considerando-o como uma decomposição da écriture artiste. Além de censurar a erudição gramatical e a prática neológica dessa ficção, ele justifica sua avaliação pejorativa pela recorrência excessiva do "tema do devaneio prantivo, e, sobretudo, pela importância cada vez maior que ganham os termos raros, o floreado e a prática de uma sintaxe do esgotamento" (1985, p.474). Nesse ponto de vista, a linguagem das narrativas decadentes promoveria uma transgressão em duplo grau: não apenas à ordenação mais cotidiana do discurso, mas até mesmo à écriture artiste.

A crítica e a historiografia brasileira analisaram a ficção decadente sob uma ótica semelhante, principalmente no que diz respeito à linguagem dessas narrativas. Enquanto para Bosi, as obras decadentes estariam apoiadas em "uma fé puramente verbal, em uma liturgia magramente literária, enfim, numa 'oração' veleitária e narcisista" (2006, p.282), para Pereira, elas apresentariam uma "verbosidade difusa e pernóstica", bem como uma série de "neologismos desnecessários" (1988, p.223-225). Esse tipo de avaliação revela uma 
compreensão limitada do estilo decadente, quando o trata como supérfluo, alambicado e com excessos desmotivados. A forma de escrita adotada por essa literatura, longe de ser mera idiossincrasia, cumpre diversas funções estéticas, ao criar formas grotescas, produzir medo como efeito de recepção e, ainda, propiciar a hesitação e o incômodo necessários às narrativas insólitas.

A própria modernidade de tal linguagem foi constantemente desconsiderada ou ignorada por parte da crítica. Seja na França das últimas décadas do século XIX ou no Brasil da Belle Époque, a écriture artiste e o estilo decadente são desenvolvidos como uma reação a uma sociedade e a uma produção intelectual consideradas cada vez mais vulgares, simplistas e populares. Em uma época na qual o escritor passa, cada vez mais, a ocupar a função de jornalista e a ter de adequar seu estilo para um largo público, crescem uma percepção de empobrecimento da língua e uma busca por novas estratégias formais. Como defende Flora Süssekind ao debater o contexto da produção nacional, "ao nascente império da imagem técnica opõe uma literatura pautada na afirmação da subjetividade e num rebuscamento que a diferenciasse da dicção de crônica dominante na produção de muitos escritores do período" (1998, p.42).

Nesse cenário, a ficção decadente prosperou com sua linguagem rebuscada, repleta de artificialismos e de neologismos, e profundamente moderna. Por meio desse estilo pouco regular, desequilibrado e, em certo sentido, também disforme, ela deu forma a um conjunto de figuras grotescas. Os seres monstruosos por elas engendrados desafiam nossas categorizações do real e são capazes de horrorizar. Não se trata, porém, do grotesco de cunho cômico, presente na produção medieval, ou de um grotesco 
meramente negativo, tal qual produzido a partir de certa parte da literatura romântica. Na literatura fin-de-siècle, o grotesco também se transforma e adquire aspectos próprios da decadência.

\section{O GROTESCO DECADENTE}

Os estudos teóricos sobre o grotesco literário seguem, em geral, duas abordagens principais: (i) a ênfase no aspecto cômico dessa poética, que teria o riso como efeito de recepção central, aproximando-a ao burlesco e à sátira (BAKHTIN, 2010); (ii) o destaque ao lado horrível e repulsivo das figuras grotescas, dando forma a uma concepção de mundo negativa e individualista (KAYSER, 1986). Enquanto o primeiro modo de tratamento tem como foco de análise obras mais ligadas ao imaginário popular medieval, como as de Rabelais, o segundo destaca, sobretudo, as narrativas modernas, a partir do século XIX e, mais especificamente, do romantismo.

Podemos destacar, ainda, outras vertentes críticas que, tendo as duas noções anteriores como basilares, apresentam algumas diferenças de entendimento e gozam de certa penetração nos estudos literários. Há, por exemplo, a compreensão da literatura grotesca como fundamental e necessariamente ambígua e paradoxal, já que seria, ao mesmo tempo, jocosa e terrível (MEINDL, 2005). Outros, no entanto, preferem abordar essa questão a partir da observação do contexto cultural de cada época e da própria estrutura das obras, a fim de revelar se é o aspecto positivo ou negativo do grotesco que ganha mais contorno (IEHL, 1997).

Todos esses entendimentos são aceitáveis e apresentam validade argumentativa, mas é importante notar que tais trabalhos teóricos sobre o grotesco, em sua maioria, não consideram como 
corpus de análise a ficção decadente. Mesmo quando se propõem a analisar o desenvolvimento dessa poética ao longo dos séculos XIX e XX, os estudos tendem a desconsiderar a literatura fin-de-siècle, como se esta não apresentasse nenhuma peculiaridade em relação às produções grotescas anteriores. Nos poucos casos em que se mencionam a perspectiva decadente e autores como Huysmans (HARPHAM, 2006), não se confere maior importância ao dado nem se inicia uma discussão mais aprofundada das possíveis peculiaridades do grotesco nessa ficção. Levantamos a hipótese de que tal lapso se deve à própria obliteração crítico-historiográfica das narrativas decadentes, que, com raras exceções, receberam juízos de valor depreciativos quando identificadas (FRANÇA \& SILVA, 2017).

Existe, no entanto, um conjunto de aspectos que aponta para uma inovadora e profícua presença do grotesco na prosa de ficção decadente. A literatura fin-de-siècle tinha como um dos seus traços principais a busca por artificialidade, isto é, por tudo aquilo que contrariasse as leis da normalidade e da natureza. Trata-se de um imperativo artístico motivado pela tentativa de produzir experiências estéticas novas, capazes de surpreender e de gerar sensações intensas no público-leitor. Por tal motivo, Isaías Mucci define essa ficção como uma "estética do artifício ou culto do simulacro [...] que cultivou, acima de tudo, o raro, o requinte, o antinatural como consequência imediata de sua filiação a Baudelaire, para quem a estranheza ou a extravagância - faz parte integrante do belo, até com ele se confundindo." (1994, p.57). Ora, a poética do grotesco é exatamente aquela especializada em gerar figuras bizarras, insólitas e antinaturais.

As narrativas decadentes exploram minuciosamente os aspectos visuais e sensoriais propiciados por essas personagens 
deformadas. Não será, no entanto, apenas sob o signo da deformidade e da feiura que essa literatura apresentará o grotesco. Além de degradadas e formadas por características tão confusas que impedem a identificação de uma unidade, as figuras grotescas serão compostas também por elementos próprios do campo das artes, tais como pinturas, cores pouco usuais, mescladas a pedras preciosas e utilizando-se de peças de vestuários refinados. Até mesmo os traços a priori negativos recebem outro tratamento: os cheiros pútridos são apresentados, por exemplo, como aromas instigantes e os físicos repulsivos como corpos originais e únicos, em nada resultantes da massificação e do materialismo que tanto esses autores criticavam na sociedade. Essa prática revela a concepção decadente de que qualquer conteúdo é passível de ser estetizado, isto é, de ser transformado em arte. Por meio do trabalho discursivo do escritor, as formas grotescas são ressaltadas em suas minúcias, em suas compleições extravagantes, naquilo que exatamente trazem de desviante e de desconhecido, para que a narrativa decadente atinja soluções artísticas inovadoras.

Se compararmos à descrição que Victor Hugo engendra do grotesco romântico, trata-se de uma concepção bastante distinta. Em seu célebre prefácio ao drama Cromwell (1827), o poeta francês defende que a exploração do grotesco seria um traço distintivo da literatura moderna em comparação à clássica. A partir da geração de figuras grotescas, capazes tanto de difundir o riso quanto a repulsa, a literatura romântica seria capaz de, antiteticamente, destacar ainda mais o caráter belo das outras imagens. Como aponta Hugo, o grotesco seria "um ponto de partida, de onde nos elevamos para o belo com uma percepção mais fresca e mais 
excitada. A salamandra faz sobressair a ondina; o gnomo embeleza o silfo" (2007, p.33).

Ainda que o autor tenha dado espaço de destaque para o grotesco em sua formulação da arte moderna, sua argumentação empreende uma compreensão dessa poética ainda em função das noções de beleza e de sublimidade. Nesse sentido, o grotesco não se justificaria sozinho em uma narrativa, já que deveria ser empregado para enfatizar aspectos positivos de outras figuras. Situação bem diferente se estabelece na ficção decadente, para qual o grotesco é um fim em si mesmo, sem necessidade de ser comparado a formas elevadas. Tais narrativas compreendem o disforme e o horrivel como possibilidades artísticas tão ou mais válidas quanto estruturas equilibradas e harmônicas.

Se, antes, na prosa romântica, o grotesco era sinônimo de feio e, portanto, oposto à beleza, na literatura decadente, ele será descrito, diversas vezes, como belo. Esse dado nos revela uma mudança bastante significativa na compreensão das categorias estéticas ao longo do século XIX. Como já expusemos, os elementos grotescos na decadência serão exaltados por sua capacidade de apresentar formas artísticas novas, além de causarem um estranhamento para a recepção. A própria écriture artiste empregada pela ficção decadente confere a essas formas legitimidade estética, já que elas têm seus aspectos sensoriais destacados continuamente e são descritas em uma linguagem que se pretende elegante, refinada e bastante refletida.

A criação de formas excêntricas e originais e o trabalho linguístico para descrever criaturas inexistentes e contraditórias são encarados como uma experimentação artística, conferindo à 
poética do grotesco um valor estético positivo. Nesse sentido, os elementos grotescos não se sustentam apenas pelos efeitos de recepção negativos que causam: para além do medo, do horror e da repulsa, o grotesco decadente é capaz de enfatizar a própria construção discursiva e literária das narrativas. Se para Bakhtin (2010) a literatura grotesca teria perdido seu caráter positivo, risonho e coletivo ao longo do século XIX, e, para Kayser (1986), essa poética expressaria uma compreensão bastante negativa do mundo, a ficção decadente apresenta uma revalorização do grotesco, compreendido como um procedimento artístico por si só bastante produtivo.

Os escritores das narrativas decadentes notaram que o grotesco exige um emprego específico dos elementos discursivos. Por não apresentarem uma formulação coesa e una, as figuras grotescas, constituídas por elementos paradoxais, impõem uma dificuldade à compreensão e à descrição linguística. As estruturas verbais, normalmente de cunho ordenador e racional, precisam também se adequar para representar seres disformes. Em virtude da dificuldade de descrição imposta por tais personagens, Harpham aponta que o "grotesco é uma palavra para a paralisia da linguagem" (2006, p.6). Não à toa, os escritores também se valeriam de termos de cunho mais geral para lidar com esses elementos, tais como "coisa", "ente" e "monstro" (HARPHAM, 2006, p.3), em uma tendência bastante próxima àquela da literatura fantástica.

Para que o grotesco se realize, é preciso, portanto, que a narrativa encontre estratégias linguísticas específicas, que sejam capazes de representar ou de sugerir o inominável. Por essa necessidade discursiva, Dominique lehl (1997, p.123) observa no 
grotesco, desde suas raízes, uma "sabedoria lúdica", um constante trabalho formal para dar conta de eventos e objetos absolutamente insólitos. Essa compreensão do grotesco como fruto da imaginação e de técnicas artísticas estava presente já em suas primeiras manifestações, ainda na arte ornamental, quando classificavamno como os "sonhos dos pintores" (KAYSER, 1986, p.20). Ao longo do tempo, no entanto, tal perspectiva foi se modificando e a arte grotesca passou a ser entendida como uma representação válida do mundo empírico. Desse modo, ela "passou progressivamente a ser aceita como um reconto mais ou menos fiel da realidade" (FRANÇA, 2017, p.225), e, mais especificamente, de uma realidade imprevisível, frequentemente assustadora e nem sempre guiada por imperativos racionais.

Ainda que a ficção decadente demonstre, de maneira bastante enfática e recorrente, a percepção de um mundo "às avessas", desconcertado e irracional, ela também recupera a tendência da arte grotesca de ser um jogo formal, um exercício de imaginação artística. Nesse sentido, a literatura fin-de-siècle sustenta esse duplo caráter do grotesco, tomando-o, simultaneamente, como modo de expressar um desconforto com a realidade e como uma maneira produtiva de se explorar as possibilidades da linguagem literária. Mesmo quando expõe o lado mais negativo da existência, por meio de situações de degradação física e moral, o grotesco decadente se compraz com suas formulações linguísticas raras, surpreendentes e de destacado apelo sensorial. Desse modo, essa realização do grotesco literário foi capaz de não apenas horrorizar, mas também de promover a fruição estética.

As deformidades do grotesco decadente, recorrentemente mescladas a elementos artísticos, a conteúdos sexuais e a doenças, 
são engendradas por um conjunto bem variado de estratégias linguístico-textuais. Para entendermos como elas são construídas, propomos a análise de trechos de duas narrativas da ficção decadente: o romance Là-bas (1891), de J.-K. Huysmans, e o conto “Agonia por semelhança” (1914), de Gonzaga Duque.

\section{ARTESANIA GROTESCA}

Os trabalhos críticos referenciados nos tópicos anteriores apresentaram diversas indicações das fórmulas discursivas empregadas nas narrativas fantásticas para propiciar os efeitos de recepção típicos dessa produção. Ao destacarmos agora os procedimentos estilísticos desenvolvidos pelas narrativas decadentes para expressar o grotesco, não pretendemos oferecer um inventário exaustivo de dados linguísticos nem esgotar as diversas possibilidades formais que o texto literário proporciona. Trata-se, sobretudo, de uma tentativa de sistematizar algumas das recorrências textuais observadas, a fim de melhor entender as especificidades da poética grotesca na ficção finde-siècle brasileira e francesa.

O romance Là-bas (1891), de J.-K. Huysmans, é exemplar de como o grotesco decadente se estabelece textualmente. A narrativa se desenvolve a partir de Durtal, um jovem escritor que decide escrever a biografia de Gilles de Rais, um personagem real da história francesa. Trata-se de um militar aristocrata do século $\mathrm{XV}$, que lutou em algumas batalhas, inclusive ao lado de Joana D'Arc. Seu nome, no entanto, está mais associado a uma série de crimes: ele foi responsável pelo assassinato e pelo estupro de inúmeras crianças em rituais de cunho satanista. Para escrever a vida do biografado, Durtal empreende diversas pesquisas sobre 
ocultismo e religião, que o levam a se indagar sobre a possibilidade de permanência de cultos demoníacos na Paris do seu tempo. 0 protagonista se envolve, então, com uma série de personagens que o fazem testemunhar práticas satanistas.

O nobre francês é também retratado como alguém obcecado pela alquimia. Em uma passagem do romance que traz um panorama sobre as buscas pela pedra filosofal na época de Gilles de Rais, Durtal se confronta com um manuscrito antigo que supostamente conteria a receita para essa descoberta. A descrição feita das imagens presentes no documento revela um conjunto de procedimentos discursivos eficientes para gerar figuras grotescas:

Há, supostamente, lá dentro, a receita da pedra filosofal, do grande elixir de quintessência e de verniz. As figuras não são precisamente claras, ele se diz, folheando os desenhos à pena realçados em cores representando em uma garrafa, sob esse título: "o coito químico", um leão verde, a cabeça embaixo em uma lua crescente; depois, nos outros frascos, estavam pombas, por vezes se elevando até o gargalo, por vezes picando uma cabeça até o fundo, em um líquido preto ou ondulado de vagas de carmim e de ouro, às vezes branco e granulado de pontos de tinta, habitado por uma rã ou uma estrela, às vezes também lácteo e confuso ou queimando em flamas de ponche, na superfície. (HUYSMANS, 1978, p.95)

Trata-se de uma passagem de difícil compreensão, repleta de elementos disformes e monstruosos. A linguagem aqui empregada, longe de ser fruto de simples erudição ou de afetação linguística, como muitos críticos apontaram em relação à ficção decadente, cumpre uma função textual: ela contribui para magnificar o efeito 
grotesco do trecho. Ora, estamos diante de frascos e líquidos possivelmente distintos, mas a linguagem aponta para uma sobreposição das imagens, para sua confusão em um mesmo objeto, a partir de associações e oposições de termos inesperadas. Para esmiuçar os recursos textuais efetivamente empregados, propomos uma análise de cada parte do trecho.

A primeira estratégia linguística, bastante recorrente nas narrativas que lidam com fenômenos sobrenaturais e monstruosos, é o destaque à imprecisão da imagem a ser apresentada. Cressot já havia identificado na prosa de Huysmans o "recurso a um termo impreciso, que dá ao seu pensamento o aspecto do inacabado e do nebuloso" (1938, p.536). Nas duas primeiras linhas do fragmento, elementos linguísticos como "supostamente" e "não são precisamente claras" indicam essa indeterminação do referente. Essas expressões dão os primeiros indícios ao leitor de que já não se está mais no plano do conhecido, do reconhecível e do propriamente real. Assim, elas cumprem a função de preparar a recepção para o surgimento de algo potencialmente inverossímil e, nesse caso, grotesco.

Na continuação do texto, ocorre um recurso imagístico pródigo em gerar figuras grotescas: a acumulação. Na terceira e na quarta linhas, lemos que Durtal folheia "desenhos à pena realçados em cores representando em uma garrafa [...]". Temos, pelo menos, três estruturas sintagmáticas de cunho adjetival ("à pena", "realçados em cores", "representando em uma garrafa") ligadas a um só termo ("desenhos"). Esse exemplo vem a corroborar a percepção de Kayser (1986, p.13) de que o grotesco costuma ocorrer a partir de um "turbulento acúmulo" de itens, como se dá na continuação 
do excerto. Quanto mais informações sobrepostas tivermos sobre uma palavra ou expressão, sem a devida coesão, como é o caso da passagem de Huysmans, maior a chance de sua indeterminação e de sua consequente deformação.

A primeira figura propriamente grotesca da transcrição surge na sequência desse mesmo período, logo após a igualmente estranha menção ao "coito químico". Trata-se de um "leão verde, a cabeça embaixo, em uma lua crescente". Identificamos nesse ponto, inicialmente, a escolha lexical inusitada, que liga um animal a uma cor que não lhe é característica. Em seguida, ocorre uma elipse de conectivo, já que não há nenhum elemento linguístico ligando o "leão" à sua "cabeça", o que reforça, para a recepção, a falta de ligação entre os elementos descritos. Afinal, se as imagens não são, em seus conteúdos, coesas, a linguagem que as expressa também não precisa ser. Há, ainda, uma indicação espacial sem referente bem definido, expressa no termo "embaixo", o que nos leva à pergunta: embaixo de onde exatamente está a cabeça do animal - do frasco, do desenho ou de si mesmo? Por fim, observamos uma combinação imagética com dados de campos semânticos totalmente distintos, com a inclusão de uma "lua crescente", em um contexto bastante imprevisto.

O prosseguimento do trecho destacado apresenta uma série de conectivos e conjunções que marcam simultaneidade e alternância, mas que, unidos, acabam por reforçar a ideia de exclusão mútua. É o que observamos na repetição de "por vezes", "às vezes" e "ou", quando se indicam os movimentos ascendentes e descendentes das pombas, bem como o caráter do conteúdo dentro do frasco, que parece se modificar constantemente. Essas 
estratégias impedem a fixação de uma imagem una do que está sendo descrito, e, para tornar a cena ainda mais contraditória e disforme, temos algumas antíteses: afinal, o líquido pode ser "preto", mas também "branco", e as aves podem estar "se elevando" ou "picando uma cabeça até o fundo".

Essa última parte do fragmento apresenta, ainda, outros aspectos importantes para a estruturação do grotesco. Há uma pluralidade de campos semânticos, condensados em poucas linhas. Primeiramente, temos termos ligados ao conjunto de cores: o líquido pode ser "preto", "carmim" e "branco"; em seguida, observamos palavras que dizem respeito à sua forma: "ondulado", "granulado", "lácteo", "confuso"3 e "queimando"; há também itens lexicais que se relacionam a pedrarias, como "ouro", a animais, como "rã", a objetos próprios da astronomia, como "estrela", e ainda a outros tipos de bebida, como "flamas de ponche". É importante destacar que todos esses sintagmas promovem outra acumulação, já que estão ligados novamente a um único termo: "líquido".

Um outro dado importante para a criação do efeito grotesco dessa parte final da passagem é, mais uma vez, a escolha lexical inusitada. Trata-se de um líquido que é habitado por uma rã ou uma estrela. Líquidos, em geral, não são habitados; muito menos por rãs ou estrelas. Percebemos ainda uma outra indicação espacial sem referente bem definido e inclusive deslocado no trecho, "na superfície". E aqui novamente se impõe a pergunta: na superfície de onde precisamente? Finalmente, um dado que contribui para a dificuldade de categorização e de identificação do objeto descrito,

3 O termo confus, no original, pode também indicar a ideia de que uma coisa está mesclada, combinada ou simplesmente fundida na outra. Trata-se de uma acepção mais comum na língua francesa, mas que também é possível em português. 
tão própria ao grotesco, é a extensão do período, que, de tão longo, impõe problemas à clareza das ideias.

A análise desse único trecho já nos permitiu a identificação de uma diversidade de procedimentos linguístico-textuais para a construção do grotesco decadente. Outros momentos de Làbas apresentam mais figuras monstruosas e distintas estratégias discursivas, sobretudo os presentes no décimo primeiro capítulo, quando Gilles de Rais vê saírem das árvores de uma floresta seres assustadores e deformados. Os recursos estilísticos arrolados não se limitam, no entanto, à obra de Huysmans ou à literatura francesa. Eles são, aliás, bastante recorrentes em outras narrativas da prosa de ficção decadente.

É o caso do conto "Agonia por semelhança” (1996 [1914]), publicado em Horto de Mágoas pelo escritor brasileiro Gonzaga Duque. Nesse texto, o grotesco é o principal procedimento de construção e de desenvolvimento da narrativa, tanto no plano temático quanto no formal. O enredo se estrutura a partir da história de Paulo que, após a leitura de um livro de Péladan, autor francês de narrativas decadentes, olha para um lenço de seda preta que lhe traz à memória a imagem de uma mulher. O protagonista, no entanto, tem dificuldade de se lembrar integralmente da figura feminina. A poética do grotesco é empregada ao longo de suas tentativas fracassadas de recriar uma forma una e fixa a partir das lembranças:

Impalpável, eterizado o corpo daquela que em vão buscava; real, maravilhosamente modelado o corpo desta que se lhe não despegava da retina. 0 outro, o procurado, surdia-Ihe agora da confusão reminiscente, em pequenas partes, pedaços que se multiplicavam e se sucediam infinitesimalmente 
- curvas ladeadas de quadris, ora deprimidos com os dolorosos raquitismos de ilíacos adolescentes, ora abundantes, rudes, da superabundância carnal das aldeãs gigantescas, desenvolvidas no afã quotidiano dos trigais e pelos remansos bucólicos das esmondas provincianas; toros de pernas - já fragmentos de colossos, avolumando, retesando as vestes, já sumidos canelos, tíbias descarnadas, macabrando na mortalha bamba do vestido... E esses retalhamentos de evocação sutilizavam-se, tenuizavam-se, lavrando nuanças atmosféricas por onde voltavam na mesma ordem caminheira de pesadelo, deslizando fantasticamente por seus olhos, sempre continuando o curso espectral de renovação sobre seus próprios esvaecimentos. (DUQUE, (1996 [1914]), p.52 - grifos meus)

Há uma convergência entre as memórias do personagem, que surgem de maneira fragmentada, e a descrição da figura da mulher, formada inicialmente apenas por pedaços. $O$ grotesco se estabelece por meio de um conjunto de antíteses entre aquilo que é ínfimo e o que é colossal no corpo dessa aparente desconhecida. Essas oposições se sustentam por hipérboles, tendo em vista que todos os aspectos físicos são extrapolados - seja quando excessivamente diminuídos, seja quando aumentados. Assim, à "superabundância carnal das aldeãs gigantescas" se opõem "sumidos canelos".

Semelhante ao trecho analisado de Là-bas, o conto de Gonzaga Duque também dá forma ao grotesco por meio de conectivos e conjunções que, em um primeiro momento, indicam alternância, para, em seguida, se anularem reciprocamente. As formas são "ora deprimidas" e "ora abundantes", e, logo depois, "já fragmentos de colossos". O recurso à mudança constante de aspectos contraditórios contribui exatamente para a impossibilidade de se 
lembrar da mulher de maneira definida. A indefinição novamente se manifesta nas imagens evocadas: o protagonista consegue ter à mente "curvas ladeadas de quadris", verdadeiros "retalhamentos de evocação". Deste modo, com um ziguezague tanto de formas quanto de discurso, Paulo luta contra o aspecto inconcluso da imagem grotesca.

A dificuldade de compreensão é acompanhada por termos que remetem a uma reação negativa do personagem ante a aparência macabra do corpo evocado. Afinal, o vestido se configura como uma "mortalha", a cena aparece como um "pesadelo", e a personagem como um espectro. Os aspectos incômodos da figura grotesca são realçados também por algumas palavras pouco frequentes na língua cotidiana, além daquelas advindas de vocabulários especializados, como o da medicina, que também impõem dificuldade de leitura. É o caso de "remansos" e "esmondas", bem como de "ilíacos" e "tíbias".

A interpenetração de linguagens especializadas e jargões profissionais na ficção decadente já fora indicada por Cressot (1938) e por Palacio (2011). É o que nos revela também o Petit glossaire pour servir à l'intelligence des auteurs décadents et symbolistes (1888). Organizada por Paul Adam e Félix Féneon, mas publicado sob o pseudônimo de Jacques Plowert, a obra apresenta um número significativo de termos advindos do campo semântico da medicina e da ciência, com aproximadamente trinta palavras. Há também diversas referências à botânica e à flora, com pelo menos quinze entradas, a cores, com treze acepções registradas, bem como à luz e à iluminação, estabelecidos em dez lexemas. Ainda que constituam amostras reduzidas em meio aos mais de quatrocentos termos, a recorrência dá indícios da influência do discurso científico 
e pseudocientífico na ficção decadente, bem como da preocupação dessa literatura com os aspectos visuais das cenas que constrói. Essa característica está representada no grotesco decadente, como deixa ainda mais evidente a continuação do conto de Gonzaga Duque:

Ressurgira. Parecia-Ihe ter surdido de uma desconhecida paragem negra de hulha, solo infecto de lodo, ambiente asfixiante de charqueadas, por onde coleia um monstro escamado de bostelas pútridas, cujas escamas viciosas, esverdinhadas e ulcerentas, destilando pus, matraqueiam soturnamente à distensão nervosa do rastejo; cuja carranca feita de um crânio descarnado de gorila tem clarões orbitais de brasidos do inferno, e ri, e ri, com a enorme fauce bárbara, emaranhada de fibrilhas chagosas de carne nauseabunda, atulhada de restos macerados da Dedicação e da Honra, besuntada de escuro sangue coagulado, de rubro sangue vivo e de excremento... (1996 [1914]), p.56 - grifos meus)

Os termos grifados se relacionam ao campo semântico da medicina, da ciência natural e, ainda mais especificamente, das doenças. A imagem da mulher se torna um animal com escamas, que se parece com um gorila, possui restos da "Dedicação e da Honra" em sua composição, além de ser, sobretudo, um personagem enfermo e repulsivo. Seu aspecto doentio é a tal ponto destacado, que mesmo seu riso é sardônico e assustador, confirmando a tendência do grotesco decadente em anular ao máximo a comicidade. Não à toa, no desfecho do conto, Paulo descobre que a imagem suscitada pelo lenço, e pela qual estava simultaneamente seduzido e horrorizado, era a de sua própria mãe. A transgressão sexual coroa, então, os desvios das formas grotescas e da linguagem decadente. 
Por fim, é importante ressaltar que a construção sintática desse trecho também apresenta uma peculiaridade: há uma mudança constante dos referentes linguísticos das orações. O "monstro escamado" tem, primeiro, suas "escamas viciosas" descritas, as quais estão "destilando pus" e "matraqueiam soturnamente", para, depois, ter sua "carranca" destacada, que apresenta uma "enorme fauce bárbara"; esta, por sua vez, será apontada como um "emaranhado de fibrilhos". Conforme o período avança, o foco e a referência discursiva vão sendo progressivamente modificados, o que colabora para a dificuldade de identificação e de classificação da figura apresentada.

Para produzir o grotesco decadente, a literatura fin-de-siècle se valeu sistematicamente da imprecisão linguística, da acumulação excessiva de qualificadores, de elipse de conectivos e conjunções, de indicações espaciais sem referente bem definido, de escolhas lexicais inusitadas, de combinação de campos semânticos bastante distintos, de antíteses, de períodos extensos que prejudicam a clareza de ideias, de mudanças nos referentes sintáticos, de neologismos, de palavras raras, de termos de outros tipos de discurso, entre outras estratégias linguístico-textuais. Nessa artesania grotesca, a ficção decadente proporcionou uma linguagem bastante moderna e instigante, que a todo momento desafia a recepção e quebra as expectativas de leitura. Desse modo, a resposta decadente à questão que introduz esse artigo foi a seguinte: para expressar o inominável, apenas um uso da linguagem igualmente imprevisível, igualmente grotesco. 


\section{REFERÊNCIAS}

BAKHTIN, Mikhail (2010). A cultura popular na Idade Média e no Renascimento: o contexto de François Rabelais. São Paulo: Hucitec.

BATALHA, Maria Cristina (2013). Pétrus Borel: trajetória de um 'menor' na cena literária francesa do século XIX. In: Revista Estação Literária, 12, 87-106.

BOSI, Alfredo (2006). História concisa da Literatura Brasileira. São Paulo: Cultrix. CRESSOT, Marcel (1938). La phrase et le vocabulaire de J.-K. Huysmans: Contribution à l'Histoire de la Langue Française pendant le dernier quart du XIXe siècle. Paris: Librairie E. Droz.

DUQUE, Gonzaga (1996 [1914]). “Agonia por semelhança”. In: Horto de mágoas. Rio de Janeiro: Biblioteca Carioca.

FRANÇA, Júlio (2017). A categoria estética do grotesco e as poéticas realistas: uma leitura de "Violação", de Rodolfo Teófilo". In: OLIVEIRA, Ana Lúcia Machado; SOARES, Marcus Vinicius Nogueira; WERKEMA, Andréa Sirihal (Orgs.) Figurações do real: literatura brasileira em foco VIII. Relicário: Rio de Janeiro. p.219-235.

; SILVA, Daniel Augusto P.(2017). Volúpias da estesia: a prosa de ficção decadente de Raul de Polillo. In: Revista Todas as Musas. São Paulo, 17, p.109-117. FURTADO, Filipe (1980). A construção do fantástico na narrativa. Lisboa: Livros Horizonte.

GARCÍA, Flavio (2012). Quando a manifestação do insólito importa para a crítica literária. In: BATALHA, Maria Cristina; GARCÍA, Flavio. (Org.). Vertentes teóricas e ficcionais do insólito. Rio de Janeiro: Editora Caetés.

HARPHAM, Geoffrey Galt (2006). On the Grotesque: Strategies of Contradiction in Art and Literature. Princeton: Princeton University Press.

HUGO, Victor (2007). Do grotesco e do sublime; tradução do prefácio de Cromwell. São Paulo: Perspectiva.

HUYSMANS, Joris-Karl (1978). Là-bas. Paris: Garnier-Flammarion.

IEHL, Dominique (1997). Le Grotesque: Que sais-je? Paris: PUF.

KAYSER, Wolfgang (1986). O Grotesco: configuração na pintura e na literatura. São Paulo: Editora Perspectiva. 
MEINDL, Dieter (2005). "The Grotesque: concepts and illustrations". In: 0 Grotesco: temas. Coimbra: Centro de Literatura Portuguesa.

MITTERAND, Henri (1985). De l'écriture artiste au style décadent. In: ANTOINE, Gérald; MARTIN, Robert. Histoire de la langue française (1880-1914). Paris: CNRS Éditions. p.467-477.

MUCCI, Latuf Isaias (1994). Ruína e simulacro decadentista: uma leitura de II Piacere, de D’Annunzio. Rio de Janeiro: Tempo brasileiro.

PALACIO, Jean de (2011). La Décadence: le mot et la chose. Paris: Les Belles Lettres/essais.

PEREIRA, Lúcia Miguel (1988). Prosa de ficção: história da literatura brasileira (de 1870 a 1920). Belo Horizonte/São Paulo: Itatiaia/EdUSP.

PLOWERT, Jacques (1888). Petit glossaire pour servir à l'intelligence des auteurs décadents et symbolistes. Paris: Bibliopole Vanier.

ROAS, David (2014). A ameaça do fantástico: aproximações teóricas. São Paulo: Editora Unesp.

(2013). O fantástico como problema de linguagem. In: ALVES, Maria Claudia Rodrigues; HATTNHER, Alvaro Luiz; RAMOS, Maria Celeste Tommasello. (Orgs.). Pelas veredas do fantástico, do mítico e do maravilhoso. São Paulo: Cultura Acadêmica; São José do Rio Preto, SP: HN.

SÜSSEKIND, Flora (1998). "O Figurino e a Forja”. In: CARVALHO, José Murilo et al. Sobre o pré-modernismo. Rio de Janeiro: Fundação Casa de Rui Barbosa.

TODOROV, Tzvetan (2010). Introdução à literatura fantástica. São Paulo: Perspectiva. 